\title{
Australian Potential for PRO-Assisted Desalination
}

\author{
L. Ribeiro $^{\text {a,b }}$, F. Helfer ${ }^{\text {a }}$, C. Lemckert ${ }^{a}$ and O. Sahin ${ }^{\text {a }}$ \\ ${ }^{a}$ School of Engineering, Griffith University, Gold Coast Campus, Australia \\ ${ }^{b}$ Email: leonardo.ribeiro@griffithuni.edu.au
}

\begin{abstract}
Seawater desalination is an energy intensive process. In Australia, the desalination industry heavily relies on the energy from fossil fuel combustion, and as such, the industry is deemed to significantly contribute to climate change. Incorporating forms of renewable energy in seawater desalination to combat increasing $\mathrm{CO}_{2}$ emissions and to help plants achieve better energy efficiency is becoming a necessary condition, but more research is needed, particularly on what sources of renewable energy would best suit desalination in terms of technical and economic aspects.
\end{abstract}

This study investigates a form of reducing the excessive consumption of energy in seawater desalination based on the utilization of the energy harnessed from the mixture of brine (the main seawater desalination byproduct) and seawater. When seawater is mixed with brine, a great amount of energy is released from the salinity gradient between these two solutions. The power generated from salinity gradients is referred to as 'osmotic power' and is completely renewable and greenhouse gas emission free. Pressure-Retarded Osmosis (PRO) is a technology used to generate osmotic power. In this study, we suggest the use of PRO to generate power for the desalination process.

Two major Australian desalination plants are used as case studies - the Perth Seawater Desalination Plant and the Southern Seawater Desalination Plant. Calculating the energy released from the salinity gradient between brine and seawater, estimating the quantity of energy that could be potentially harnessed using the PRO technology and calculating the energy offset in the desalination process, were the main objectives of this study.

The maximum energy extractable during the mixing of solutions with concentrations similar to brine and sweater in a PRO system is approximately 1.1 MW per $\mathrm{m}^{3} \mathrm{~s}^{-1}$ of seawater (Helfer and Lemckert, 2015). In this current study, a plant efficiency of $70 \%$ was adopted (Loeb, 2001), making the extractable energy 0.77 MW per $\mathrm{m}^{3} \mathrm{~s}^{-1}$ of seawater.

For Perth Seawater Desalination Plant and the Southern Seawater Desalination Plant, which produce about $60 \mathrm{GL}$ and $140 \mathrm{GL}$ of brine per year, respectively, the combined amount of osmotic power that could be generated is $43 \mathrm{GWh}$. This would correspond to approximately $7 \%$ of the requirements of energy for the seawater desalination process. The preliminary results showed in this study are promising, but an investigation to estimate the costs involved in building a PRO plant is required in order to determine the financial viability of PRO-assisted desalination.

In a future study, a different scheme will be investigated, using Australian desalination plants operating in "stand-by mode" as case studies. It has been suggested that, for such plants, the membrane modules of the RO process could be used under PRO, rather than RO conditions, during times when the plant is not being required for freshwater production. Under this proposed configuration, the utilization rate of the desalination structure would be significantly augmented, as the plant would be generating energy instead of producing freshwater in periods of high water availability; conversely, it would be producing freshwater, instead of generating energy, in periods of severe water scarcity. Low plant utilization rates have been a common public concern in several coastal cities in Australia and discussions towards this issue has sparked debate of how to justify costs of constructing and maintaining desalination infrastructure. Designing these plants in such a way that they could be utilised for dual purpose (ie, PRO power and RO desalination) would be one way to justify these high investments. The results of this investigation will be reported in a future publication.

Keywords: Desalination, renewable energy, osmotic power, salinity 


\section{INTRODUCTION}

Harnessing the energy from salinity gradients has been a growing subject of study in recent years. PressureRetarded Osmosis (PRO) is one of the technologies available to harness the energy released when solutions with different salinities mix. PRO works on the basis of a semipermeable membrane which separates solutions of low and high salt concentrations (feed and draw solutions respectively). As the side containing the solution with low salt concentration permeates the side containing the solution with high salt concentration, there is volume expansion on the high concentration solution side. Pressure builds up due to this expansion in volume, from which work can be extracted by a turbine, depressurizing the high concentration side, generating osmotic power. Apart from zero carbon dioxide emission, PRO is capable of producing power with less periodicity than other conventional sources of renewable energy, abundance and low environmental impacts (Helfer et al., 2014).

Several factors have hindered the implementation of PRO in large scales. The difficulty in finding membranes with appropriate technology for use in PRO, the high susceptibility to internal concentration polarization of commercially available membranes (the gradual build-up of salts on membrane interfaces that reduces their effectiveness) and low mechanical resistance of membranes to high pressures are the main factors behind the low competitiveness of PRO when compared to other types of renewable energy sources. However, the rapid growth in membrane technology, combined with large scale production of membranes, is gradually changing this scenario.

PRO investigation initially considered the combination of freshwater as the feed solution and salt water as the draw solution. Satisfactory results, in conjunction with advancements in membrane technology, led to the adaptation of this renewable source of energy generation to other types of combinations of solutions with various salinities, such as the use of brackish water $v$ s freshwater, brine (the by-product of the desalination process) vs seawater, amongst others.

It has been suggested by Kim et al. (2012b) and Palacin et al. (2012) the use of PRO to provide osmotic power for Seawater Reverse Osmosis (SWRO). As well known, desalination is an energy intensive process, usually dependent on conventional sources of energy. In Australia, for example, the desalination industry heavily relies on the energy from fossil fuel combustion, and as such, the industry is deemed to significantly contribute to climate change. Hence, incorporating forms of renewable energy in seawater desalination is becoming a necessary condition.

PRO-assisted SWRO desalination is a term referring to the symbiotic relationship between desalination and osmotic power, under which power is generated in a separate PRO plant, attached to the desalination plant (Helfer and Lemckert, 2015). Reject brine from the desalination process is used as the draw solution in the PRO plant, and seawater is used as the feed solution. PRO-assisted desalination is intended to not only provide renewable energy to desalination, but also minimize the environmental impacts of the direct discharge of brine in the natural environment. A conceptual model of a PRO-assisted desalination plant is presented in Figure 1.

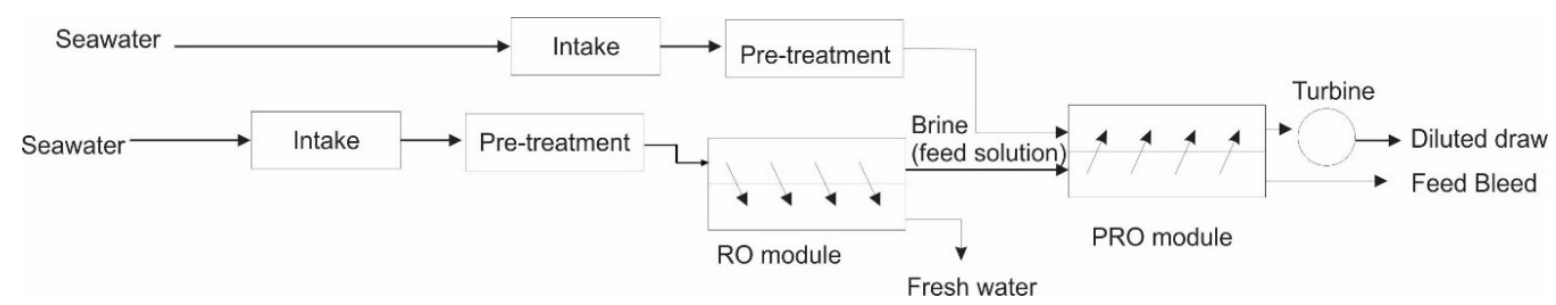

Figure 1. Conceptual model of a PRO - assisted desalination scheme (Helfer and Lemckert, 2015)

In this context, the objectives of this study are to estimate how much power can be generated under a PROassisted desalination process, as well as how much of the energy used in the desalination process can be supplied by PRO.

Intuitively, it can be said that the proposed PRO-assisted desalination scheme is only feasible in desalination plants that operate for long periods of time, generating a significant quantity of brine. As such, for this investigation, the Australian desalination plants supplying water to the city of Perth (the Perth Seawater Desalination Plant and the Southern Seawater Desalination plant), which operate at full capacity for almost $90 \%$ of the time, are used as case studies in this investigation. 


\section{METHODOLOGY}

\subsection{Understanding Pressure- Retarded Osmosis and Osmotic Power Generation}

In a PRO plant, the fluxes of two solutions of different salinities are kept separated by a semipermeable membrane in membrane modules similar to those used in the desalination industry. As the less concentrated solution side (feed solution) has a lower osmotic pressure, water will flow from the less concentrated solution side to the more concentrated solution side (draw solution), increasing the volume of the draw solution side. As this volume is increased, pressure acts on the expanding volume, which can be used to generate power.

Recent studies concluded that the combination of seawater $v s$ brine (or a similar combination that can result

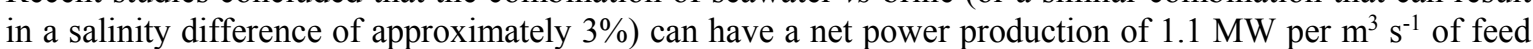
solution in a PRO system (Helfer and Lemckert, 2015) - refer to Table 1. Accounting for inefficiencies along the process of extracting work and allowing for inefficiencies of rotating machines such as pumps $(88 \%$ efficiency), motors and generators (98\% efficiency), hydro-turbines (92\% efficiency) (Loeb, 2001), losses due to friction of water in pipes and concentration polarization (reduction in effective osmotic pressure differential due to salt build-ups at the water-membrane interface), it is reasonable to say that approximately $70 \%$ of this power can be harnessed.

Table 1. Osmotic power production potential from the combination of brine and seawater (Helfer and Lemckert, 2015)

\begin{tabular}{|c|c|c|c|c|}
\hline $\begin{array}{l}\text { Feed solution (average salt } \\
\text { concentration and osmotic } \\
\text { pressure) }\end{array}$ & $\begin{array}{l}\text { Draw solution (average salt } \\
\text { concentration and osmotic } \\
\text { pressure) }\end{array}$ & $\begin{array}{l}\text { Water flux } \\
\text { through } \\
\text { membrane, } J \\
\left(\mathrm{~L} \mathrm{~m}^{-2} \mathrm{~h}^{-1}\right)^{1}\end{array}$ & $\begin{array}{l}\text { Achievable } \\
\text { power density } \\
\left.(\mathrm{W} \mathrm{m})^{-2}\right)^{2}\end{array}$ & $\begin{array}{c}\text { Realistic power } \\
\text { production per } \mathrm{m}^{3} \mathrm{~s}^{-1} \text { of } \\
\text { feed solution } \\
(\mathrm{MW})^{3}\end{array}$ \\
\hline Seawater $(\approx 3.5 \%, 28.5$ bar $)$ & $\begin{array}{c}\text { Concentrated brine from } \\
\text { desalination }(\approx 6 \%, 48.8 \text { bar })\end{array}$ & 15.3 & 4.3 & 1.1 \\
\hline \multicolumn{5}{|c|}{$\begin{array}{l}{ }^{1} \text { Water flux, } J \text { : calculated using the equation: } J=A(\Delta \pi-\Delta P) \text { where } \Delta \pi=\pi D-\pi F \text {, where } \pi D \text { is the osmotic pressure in the draw } \\
\text { solution and } \pi F \text { is the osmotic pressure in the feed solution, and } \Delta P=P_{D}-P_{F} \text {, where } P_{D} \text { is the applied pressure in the draw solution and } \\
\left.P_{F} \text { is the applied pressure in the feed solution (typically } 0\right) . A \text { is the intrinsic water permeability of the membrane, assumed as } 1.5 \mathrm{~L} \mathrm{~m}^{-2} \\
\mathrm{~h}^{-1} \text { bar }^{-1} \text { for this calculation (Helfer et al., 2014). } \\
{ }^{2} \text { Power density: given by the product of the operating pressure, } P_{D} \text {, and the water flux, } J \text {. The operating pressure was assumed as half } \\
\text { the osmotic pressure differential, as suggested in the literature (Gerstandt et al., 2008, Skilhagen, 2010, Skilhagen et al., 2008). } \\
{ }^{3} \text { Power per } \mathrm{m}^{3} \mathrm{~s}^{-1} \text { of feed solution: given by the product of the operating pressure and the unit flow of feed solution. }\end{array}$} \\
\hline
\end{tabular}

The product of the volume flux through the membrane, $J$, the total membrane area and the operating pressure gives the total power production potential of a PRO plant. For example, a PRO plant equipped with 500,000 $\mathrm{m}^{2}$ of membranes allowing a flux of salt water of approximately $15 \mathrm{~L} \mathrm{~m}^{-2} \mathrm{~h}^{-1}$, and operating at an applied pressure of 13 bar, would have a power output of $2.7 \mathrm{MW}$. Here, it is important to mention the necessity of membrane improvement for application under PRO conditions. Membrane improvement focusses on membrane properties that allow for higher fluxes; that is, for more volume of feed per unit area of membrane. If the maximum theoretical flux, $J$, estimated based on membrane permeability and osmotic and hydraulic pressure differentials, could be achieved in reality (i.e., approximately $35 \mathrm{~L} \mathrm{~m}^{-2} \mathrm{~h}^{-1}$ ), then the abovementioned amount of membranes would be generating $6 \mathrm{MW}$. The main issue with the currently available membranes are their high susceptibility to concentration polarization, which refers to the accumulation of salts at the water-membrane interface - a phenomenon that affects the osmotic pressure differential, and therefore the water flux through the membrane (Helfer and Lemckert, 2015, Yip and Elimelech, 2011, Yip et al., 2011).

As mentioned above, the power production from a PRO plant operating on the basis of seawater and brine could be approximately 1.1 MW per $\mathrm{m}^{3} \mathrm{~s}^{-1}$ of feed solution (seawater) (Helfer and Lemckert, 2015) as shown in Table 1. In this study, an efficiency of $70 \%$ was assumed, making the power output $0.77 \mathrm{MW}$ per $\mathrm{m}^{3} \mathrm{~s}^{-1}$ of seawater.

For the purpose of this study, a recovery rate (a percentage of the amount of seawater which is turned into freshwater) of $42 \%$ (Fritzmann et al., 2007) is considered (i.e. for every $100 \mathrm{~L}$ of seawater pumped into the membranes by the desalination plant, $42 \mathrm{~L}$ is turned into potable water for human consumption, while the remaining $58 \mathrm{~L}$ is brine which will be used as the draw solution by the PRO plant).

In order to obtain results for PRO energy and power outputs, the total amount of draw solution (brine waste) was calculated using the aforementioned parameters (total water production from RO, recovery rate, osmotic power plant efficiency and PRO power production potential). This amount also determines the amount of 
feed solution (seawater) which is pumped through the membranes, as $1 \mathrm{~m}^{3} \mathrm{~s}^{-1}$ of draw solution requires $1 \mathrm{~m}^{3}$ $\mathrm{s}^{-1}$ of feed solution (Loeb, 2001). In this context, by knowing the amount of feed solution available, it is possible to estimate the power generated by the PRO plant.

\subsection{Case Studies}

The investigation of a PRO-assisted desalination scheme was based on two Australian desalination plants located in the Perth region (Perth Seawater and Southern Seawater Desalination Plants). These two desalination plants have been operating continuously for the past years, almost always at full capacity; therefore, brine (the reject of the desalination process) is also being generated at a constant rate and significant quantities. As postulated by many authors, such as Kim et al. (2012a), Kim et al. (2012b), Kim and Elimelech (2013), Sim et al. (2013), Palacin et al. (2012), Helfer and Lemckert (2015) and Helfer et al. (2014), this brine could be used as the draw solution, while seawater could be used as the feed solution in a PRO module to generate power for the desalination plant. This scheme is comprised of two separate units, one for desalination and one for PRO. The desalination unit provides drinking water to the local water grid, and the PRO unit provides power to the desalination plant. The amount of power that could be generated with this combination of solutions is $0.77 \mathrm{MW}$ per $\mathrm{m}^{3} \mathrm{~s}^{-1}$ of seawater (Helfer and Lemckert, 2015). An important aspect of this type of configuration is that power generation in the PRO-assisted desalination scheme would only be limited by the amount of brine produced by the desalination plant. Therefore, the estimation of the amount of brine produced by the two plants under study is one of the key steps in these simulations.

The Perth Desalination Plant, located in the Perth metropolitan area, has a total capacity of 139 ML per day. It operates on average 321 days per year, producing approximately $45 \mathrm{GL}$ of freshwater. When operational, the Perth Desalination Plant works at its full capacity. Likewise, the Southern Seawater Desalination Plant, also located in the Perth metropolitan area, has been continually operating at more than $80 \%$ of its full capacity. This plant has a water production capacity of $274 \mathrm{ML}$ per day (100 GL per year). Due to the region's low water availability, both plants have been highly utilized. More than half of Perth's water needs is supplied by water desalinated at these two desalination plants (Western Australia Water Corporation, 2015).

The Perth Desalination Plant consumes 185,000 MWh of electricity to produce about 45 GL of water per year (Western Australia Water Corporation, 2006). This energy is enough to supply 28,000 four-person households (assuming an annual consumption of $6,617 \mathrm{kWh}$ per household according to the Australian Government (2015)). This requires an uninterrupted supply of $24 \mathrm{MW}$ of power to the plant for water production (or 14.1 MW for every $1 \mathrm{~m}^{3} \mathrm{~s}^{-1}$ of freshwater produced from desalination).

Just as the Perth Seawater Desalination Plant, the Southern Seawater Desalination Plant, which also supplies water to Perth and has a full capacity of $100 \mathrm{GL}$ per year, consumes on average 411,000 MWh of energy per year, or $51 \mathrm{MW}$. These values of power consumption are reasonably acceptable, as according to Hoang et al. (2009), on average, the production of $1 \mathrm{~m}^{3} \mathrm{~s}^{-1}$ of freshwater consumes approximately $12 \mathrm{MW}$ of power in reverse osmosis desalination.

\section{DISCUSSION AND CONCLUSIONS}

As seen in Table 2, calculations for the proposed PRO-assisted desalination scheme, using the Perth Seawater Desalination Plant as a test plant, produced optimistic results. It was calculated, considering the previously discussed parameters, that approximately $13 \mathrm{GWh}$ per year of osmotic energy (1.7 MW) could be potentially produced by a PRO plant receiving the brine from the desalination process. This amount of energy could possibly offset approximately $7 \%$ of the total energy used by the reverse osmosis desalination plant, thus drastically reducing energy requirements of the plant.

Likewise, the Southern Seawater Desalination Plant, under the proposed PRO-assisted desalination scheme, was able to produce approximately $30 \mathrm{GWh}$ of osmotic energy per year (3.8 MW), also offsetting $7 \%$ of the total energy necessary to run the Southern Seawater Desalination Plant. 
Table 2. Estimated power offset for Perth Desalination Plant and Southern Seawater Desalination Plant

\begin{tabular}{|c|c|c|c|c|c|c|c|}
\hline & $\begin{array}{c}\text { Water } \\
\text { Production } \\
\text { Full Capacity } \\
\left(\text { GL year }{ }^{-1}\right)\end{array}$ & $\begin{array}{c}\text { Brine } \\
\text { Production } \\
\left(\text { GL year }^{-1}\right)\end{array}$ & $\begin{array}{c}\text { Energy } \\
\text { Consumed by } \\
\text { The Plants for } \\
\text { RO } \\
\left(\text { GWh year }{ }^{-1}\right)\end{array}$ & $\begin{array}{c}\text { Power } \\
\text { Consumed by } \\
\text { The Plant for } \\
\text { RO (MW) }\end{array}$ & $\begin{array}{l}\text { PRO Produced } \\
\text { Energy } \\
\left(\text { GWh year-1 }^{-1}\right)\end{array}$ & $\begin{array}{l}\text { PRO Power } \\
\text { Output (MW) }\end{array}$ & $\begin{array}{c}\text { Offset } \\
(\%)\end{array}$ \\
\hline Perth & 45 & 62.1 & 185 & 24 & 13.3 & 1.7 & 7 \\
\hline $\begin{array}{l}\text { Southern } \\
\text { Seawater }\end{array}$ & 100 & 138.1 & 411.1 & 53.4 & 29.5 & 3.8 & 7 \\
\hline
\end{tabular}

Although most assumptions taken into account in this study were based on theoretical results, it is possible to infer with this preliminary investigation, that the use of PRO can potentially reduce the energy requirements of reverse osmosis desalination. Advancements in membrane technology, the use of more energy efficient pumps and a more advanced and automated control system can possibly improve results in the future.

It is also necessary to consider financial constraints that were not included in this study. A study to estimate the costs involved in building a PRO unit next to a desalination plant is required. Intuitively, as both desalination and energy production with PRO utilize similar membrane-based technologies, it is likely that PRO-assisted schemes will show financial viability.

\section{FINAL CONSIDERATIONS}

In a future study, a different scheme will be investigated, using Australian desalination plants that remain idle for long periods of time as case studies. This is the case of regions where these structures have been built as a form of "water insurance" - i.e., to supply freshwater in dry years, when rain-dependent sources are not able to meet the local demands (Sahin et al., 2015). Helfer and Lemckert (2015) suggest that these plants could be utilised for power production during these times when they are not operating for freshwater production. This scheme is depicted in Figure 2. In this scheme, the membrane modules of the reverse osmosis desalination plants are used under PRO rather than reverse osmosis conditions when the plant is not being required for freshwater production. Freshwater is diverted into the plant as feed solution, and seawater is pumped into the modules as draw solution. Given that this scheme uses freshwater as feed solution, the success of the system is predicated to freshwater from rivers and lakes being abundant in the environment. Under this proposed configuration, the utilization rate of the desalination structure would be significantly augmented, as the plant would be generating energy instead of producing freshwater in periods of high water availability; conversely, it would be producing freshwater, instead of generating energy, in periods of severe water scarcity. Low plant utilization rates has been a common public concern in several coastal cities in Australia, and discussions towards this issue has sparked debate of how to justify costs of constructing and maintaining desalination infrastructure (Ferguson, 2014). Designing these plants in such a way that they could be utilised for dual purpose (ie, PRO power and desalination) would be one way to justify these high investments (Helfer and Lemckert, 2015). The results of this investigations will be reported in a future publication.

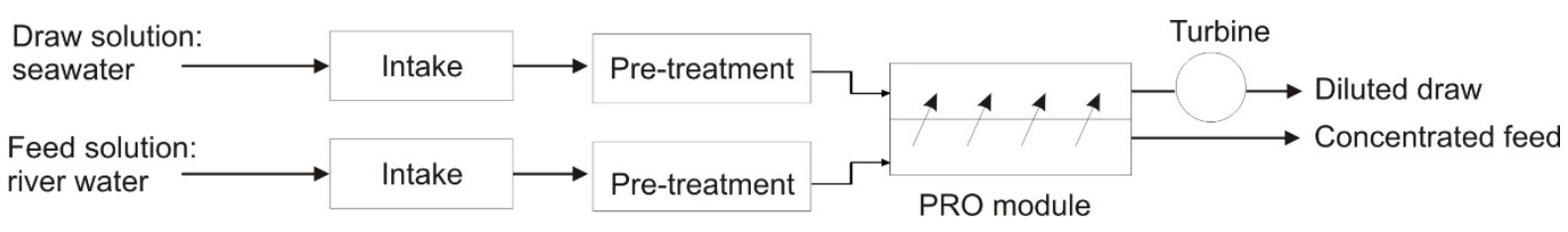

Figure 2. A PRO-RO hybrid scheme proposed for desalination plants operating in "stand-by mode" (Helfer and Lemckert, 2015)

\section{ACKNOWLEDGMENTS}

Funding for this project was provided by the Griffith Climate Change Response Program, the Griffith Sciences and the CNPq - Conselho Nacional de Desenvolvimento Científico e Tecnológico (Brazil). 


\section{REFERENCES}

AUSTRALIAN GOVERNMENT. 2015. Average household electricity usage [Online]. Available: http://energymadeeasy.gov.au/bill-benchmark/results/3660/4 [Accessed March 24 2015].

FERGUSON, J. 2014. Billions in desalination costs for not a drop of water. The Australian, October 18, 2014.

GERSTANDT, K., PEINEMANN, K. V., SKILHAGEN, S. E., THORSEN, T. \& HOLT, T. 2008. Membrane processes in energy supply for an osmotic power plant. Desalination, 224, 64-70.

FRITZMANN C, LÖWENBERG J, WINTGENS T, MELIN T. 2007. State-of-the-art of reverse osmosis desalination. Desalination , 216, 1-76.

HELFER, F. \& LEMCKERT, C. 2015. The Power of Salinity Gradient: An Australian Example. Renewable \& Sustainable Energy Reviews, 50, 1-16.

HELFER, F., LEMCKERT, C. \& ANISSIMOV, Y. G. 2014. Osmotic power with Pressure Retarded Osmosis: Theory, performance and trends - a review. Journal of Membrane Science, 453, 337-358.

HOANG, M., BOLTO, B., HASKARD, C., BARRON, O., GRAY, S. \& LESLIE, G. 2009. Desalination in Australia. Canberra: Report for the CSIRO Water for a Healthy Country National Research Flagship.

KIM, J., LEE, J. \& KIM, J. H. 2012a. Overview of pressure-retarded osmosis (PRO) process and hybrid application to sea water reverse osmosis process. Desalination and Water Treatment, 43, 193-200.

KIM, J., PARK, M. \& KIM, J. H. 2012b. Feasibility analysis of hybrid seawater reverse osmosis (SWRO) and pressure retarded osmosis (PRO) system. In: 3rd Osmosis Membrane Summit. Barcelona.

KIM, Y. C. \& ELIMELECH, M. 2013. Potential of osmotic power generation by pressure retarded osmosis using seawater as feed solution: Analysis and experiments. Journal of Membrane Science, 429, 330337.

LOEB, S. 2001. One hundred and thirty benign and renewable megawatts from Great Salt Lake? The possibilities of hydroelectric power by pressure retarded osmosis. Desalination, 141, 85-91.

PALACIN, L. G., TADEO, F., PRADA, C. D. \& TOUATI, K. 2012. Evaluation of the recovery of osmotic energy in desalination plants by using pressure retarded osmosis. Desalination and Water Treatment, 51, 360-365.

SAHIN, O., STEWART, R. A. \& HELFER, F. 2015. Bridging the Water Supply-demand Gap in Australia: Coupling Water Demand Efficiency with Rain-independent Desalination Supply. Water Resources Management, 29, 253-272.

SIM, V. S. T., SHE, Q., CHONG, T. H., TANG, C. Y., FANE, A. G. \& KRANTZ, W. B. 2013. Strategic colocation in a hybrid process involving desalination and Pressure Retarded Osmosis (PRO). Membranes, 3, 98-125.

SKILHAGEN, S. E. 2010. Osmotic power - a new, renewable energy source. Desalination and Water Treatment, 15, 271-278.

SKILHAGEN, S. E., DUGSTAD, J. E. \& AABERG, R. J. 2008. Osmotic power - power production based on the osmotic pressure difference between waters with varying salt gradients. Desalination, 220, 476-482.

WESTERN AUSTRALIA WATER CORPORATION. 2006. Desalination [Online]. Paper prepared for the 2006 Australian State of the Environment Committee, Department of the Environment and Heritage, Canberra. Available: http://www.environment.gov.au/topics/science-and-research/stateenvironment-reporting/soe-2006-desalination [Accessed March 24 2015].

WESTERN AUSTRALIA WATER CORPORATION. 2015. Solutions to Perth's Water Supply: Desalination [Online]. Perth. Available: http://www.watercorporation.com.au/water-supply-andservices/solutions-to-perths-water-supply/desalination [Accessed March 24 2015].

YIP, N. Y. \& ELIMELECH, M. 2011. Performance Limiting Effects in Power Generation from Salinity Gradients by Pressure Retarded Osmosis. Environmental Science \& Technology, 45, 10273-10282.

YIP, N. Y., TIRAFERRI, A., PHILlIP, W. A., SCHIFFMAN, J. D., HOOVER, L. A., KIM, Y. C. \& ELIMELECH, M. 2011. Thin-Film Composite Pressure Retarded Osmosis Membranes for Sustainable Power Generation from Salinity Gradients. Environmental Science \& Technology, 45, 4360-4369. 